\title{
Aesthetic Values of Lakes and Rivers
}

\author{
Jay R. Corrigan \\ Department of Economics, Ascension Hall, Kenyon College, Gambier, OH, USA. \\ corrigan@kenyon.edu.
}

Kevin J. Egan

Department of Economics, University of Toledo, 4140E University Hall, Toledo, OH 43606 USA. kevin.egan@utoledo.edu.

John A. Downing

Department of Ecology, Evolution and Organismal Biology, Iowa State University, 253 Bessey Hall, Ames, IA 50011 USA. downing@iastate.edu.

July 2007

Key words: Aesthetic value, contingent valuation, economic value, environmental valuation, revealed preference, stated preference, travel cost method, water quality.

Acknowledgments: We thank Joseph Herriges and Catherine Kling for their helpful comments. This work was supported by grants from the Iowa Department of Natural Resources, the United States Environmental Protection Agency, and the City of Clear Lake, IA, USA. 


\section{Synopsis}

The aesthetic quality of water resources is often assumed to be valuable to society, yet few robust estimates of this value have been reported in the limnological literature. Because entire lakes and rivers are not bought and sold regularly, their aesthetic value cannot be determined by differences in market prices. Therefore, economically valid estimates must be determined by methods that estimate willingness to pay (WTP) for aesthetic value. Methods for and example results of an environmental valuation study to estimate local residents' and visitors' WTP for improved aesthetic quality in Clear Lake (Iowa, USA), a eutrophic, natural lake are presented. Both revealed preference and stated preference techniques for estimating value are considered. In the revealed preference application, WTP is inferred by comparing the number of times survey respondents planned to visit the lake given its current conditions with the number of times they would plan to visit if the lake's water quality were improved. In the stated preference application, WTP is inferred by presenting survey respondents with a hypothetical ballot initiative offering improved water quality and resulting higher taxes associated, then estimating the highest tax bill at which the ballot initiative would have passed. 


\section{Introduction}

The various recreational services provided by lakes and rivers - fishing, swimming, boating, hunting, picnicking, or nature appreciation in general—are all enhanced by the body of water's natural beauty. For example, see Figure 1. Economists can estimate the value of these recreational services as well as how that value changes as the aesthetic quality of a lake or river changes. The task is important given that most lakes and rivers are public goods, with government agencies having the ability to preserve or improve their aesthetic quality. When policymakers are provided with estimates of the aesthetic value of a lake or river, the value of the biodiversity it supports, and the value of the recreational opportunities it provides, these benefits can be compared against the cost of government policies aimed at maintaining or improving water quality. This careful weighing of benefits and costs should result in a more efficient provision of environmental amenities.

$<$ Figure 1 near here $>$

However, the valuation task is complicated by the fact that public goods, and therefore the aesthetic quality of public goods, are nonmarket goods in that they are provided by the government and not by the interaction of buyers and sellers in a market. Occasionally entrance fees are charged at lakes or rivers; however, these fees are generally nominal and offer little information about the value of the lake or river to the visitor.

Economists estimate the value of all goods, including nonmarket goods such as the aesthetic value of water resources, using the concept of maximum willingness to pay (WTP), which is the maximum monetary value an individual would pay for a certain good. In other words, WTP represents the value of other goods and services an individual is willing to forgo in order to enjoy the good in question. 
For example, consider a cost-benefit analysis of undertaking a water quality improvement project at a lake. The analyst quantifies tradeoffs individuals are willing to make in exchange for improved water quality (measured by WTP) and compares these to the actual costs of cleaning up the lake, such as public resources to fund clean-up efforts or private costs associated with altering land use.

This approach is in contrast to studies of local economic impact, which estimate the value of goods or services marketed near a lake or river. Such studies are of interest to local communities who benefit commercially from tourism, but are not appropriate measures of the resource's intrinsic value used in cost-benefit analysis. One reason is that sales that occur locally due to tourism, such as camping fees or restaurant sales, are likely just being transferred from somewhere else and are therefore not a net increase in society's overall wellbeing. Moreover, local sales receipts may not be correlated with a resource's intrinsic value. For example, when there are no businesses near a lake or river to capitalize on its presence that does not mean that it has no value. On the contrary, a resource's value is often enhanced by its remoteness or its pristine qualities.

For most goods, a market readily exists where equilibrium prices signal the marginal value of the resource, for example farm land. However, for public goods such as the aesthetic value of lakes and rivers, there is no market transaction to measure value. Economists must gather nonmarket data to value public goods. Techniques for estimating the value of nonmarket goods fall into two broad categories: revealed preference and stated preference. When using revealed preference techniques, economists observe individuals' actual choices for goods related to the aesthetic quality of lakes and rivers. The most common related good to observe is the number of trips taken to nearby water resources. As will be discussed below, the cost individuals 
are willing to incur traveling to a site can be used to infer the value they place on it, thus revealing their preferences for the various characteristics the site possesses. In other words, individuals demonstrate that they are willing to sacrifice more of their leisure time or time spent earning income as they are observed traveling greater distances for higher water-quality resources. In this way, economists infer the value placed on the aesthetic quality of public goods. Another related good used to reveal values of aesthetic quality is the value of homes near lakes and rivers. In this case economists observe the premium that households are willing to pay for a home near a water resource with high aesthetic quality. This premium is the inferred value of aesthetic quality.

Stated preference techniques involve asking individuals hypothetical questions that directly indicate the value they place on a resource or a change to the resource. The most commonly used stated preference technique is the contingent valuation method. Here, survey respondents may be asked whether they would be willing to pay higher property taxes in exchange for improved water quality, giving the researcher direct information on the monetary value respondents place on a change in the resource.

Returning to the willingness to pay (WTP) concept, economists divide all value for water resources into three categories: use value (WTP for the direct use of the resource), option value (WTP for the future ability to visit the resource), and nonuse or existence value (WTP for the environmental resource even though the resource has never and will never be visited). Revealed preference techniques such as the travel cost method only estimate use value, as economists can only infer values from individuals' use of the water resource. In contrast, stated preference techniques such as the contingent valuation method estimate the full WTP including option value 
and existence value, as individuals are directly providing their WTP for improved water quality conditions whether they currently use the resource or simply derive value from its existence.

In what follows we provide background information on both the travel cost and contingent valuation methods. We then use these techniques to estimate WTP for improved water quality in a spring-fed glacial lake in north-central Iowa. Assuming a body of water's aesthetic value is tied directly to water quality measures such as clarity, color, and the frequency of algae blooms, our results can be interpreted as estimates of aesthetic value.

\section{Revealed preferences and the travel cost method}

The travel cost method, also known as recreation demand modeling, requires collecting information on the water resources individuals choose to visit and the number of times they visit each site. Economists estimate the effort individuals expend in visiting a resource by calculating the total distance traveled and total time spent in transit. The distance and time are monetized by assuming a cost per mile and cost per hour, labeling these as travel costs, which are the price of visiting the recreational site. Holding all else constant, individuals will visit a recreational site more often when it is nearby and therefore has low travel costs. The recreation demand for a site is depicted in Figure 2, with the recreation demand curve showing the inverse relationship between travel costs and individuals' chosen number of trips to the site. Armed with the total trips, travel costs, and other important site characteristics such as aesthetic quality, economists use regression analysis to explain the trip variation (i.e., the dependent variable) as a function of site characteristics (i.e., the independent variables like travel cost and aesthetic quality).

$<$ Figure 2 near here $>$ 


\section{Inferring WTP for aesthetic quality}

Inferring individuals' WTP for aesthetic quality using the travel cost method requires introducing a related concept, consumer surplus. Consumer surplus (CS) is the difference between individuals' WTP to visit a recreational site and the travel costs actually incurred. The area under the recreation demand curve represents the maximum visitors are willing to pay for access to a resource given their chosen number of trips. Referring again to Figure 2, visitor $i$ incurs travel cost Cost $_{i}$ per trip to the recreational site and therefore chooses to take $y_{i}$ trips per year. Area acd 0 represents the maximum visitor $i$ would be willing to pay to take $y_{i}$ trips, while area bcd0 represents the travel cost she actually incurs. The difference between these two areas is her CS. In this case, area abc. CS can be thought of as the net benefit the visitor derives from having access to the resource.

To better understand how a change in CS can be used to estimate aesthetic value, consider panels a and $\mathrm{b}$ of Figure 3. The recreation demand curve in panel $\mathrm{b}$ is drawn further out, reflecting that visitors choose to take more trips as aesthetic quality improves. Note that while travel cost is the same across both recreational sites, visitor $i$ derives more CS from the site with superior aesthetic quality.

$<$ Figure 3 near here $>$

The final step in calculating the value visitors derive from aesthetic improvements is to estimate the additional CS individuals gain from visiting an improved water resource. In Figure 4, visitor $i$ reveals her WTP for aesthetic quality by reporting that she would take more trips to the site if its aesthetic quality were improved ( $y_{i 2}$ vs. $\left.y_{i 1}\right)$. Holding all else constant, including per-trip travel costs, the additional area under the higher recreation demand curve reflects visitor $i$ 's WTP for improved aesthetic quality. WTP for improved aesthetic quality is calculated as 
WTP for aesthetic improvements $=$

CS with aesthetic improvements - CS with current conditions.

WTP for improved aesthetic quality is depicted graphically as area abcd in Figure 4.

$<$ Figure 4 near here $>$

Given a long time horizon, an analyst could observe individuals' changing trip levels to the same recreational site as aesthetic conditions change. In practice, however, economists generally present survey respondents with proposed aesthetic changes, then ask the respondents how they would change their trip behavior if these changes were to take place. This hypothetical trip information is called contingent behavior trips, as these trip levels are contingent upon the proposed changes.

The travel cost method has been used to estimate the value of water resources for over 45 years, and since 1979 federal agencies in the USA have been required to estimate the value of recreation benefits for projects involving high visitation levels. For example, travel cost methods are used to estimate damage assessment payments by companies that lower the aesthetic quality of a water resource, such as after the 1989 Exxon Valdez oil spill in Alaska. However, the primary use of the travel cost method is to estimate recreational values (i.e., use values) utilized in cost-benefit analyses. The primary objective of cost-benefit analysis when applied to water resources is to provide policymakers with information about the level of public spending warranted in protecting or improving those resources. The travel cost application discussed in the next section was designed to provide this type of information, as it focuses on changes in lake visitation rates resulting from state-funded water quality improvements.

\section{An application of the travel cost method}

The travel cost method's usefulness can best be seen in the context of an example. Here we 
summarize the results of a study estimating the value visitors place on improving water quality at

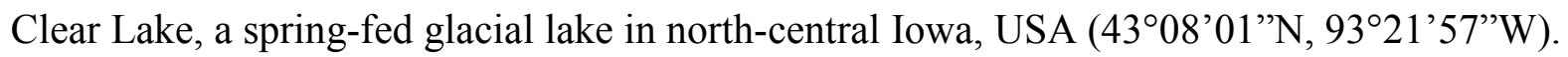

Clear Lake is a 1,470 hectare eutrophic lake with mean total phosphorus of $188 \mu \mathrm{g} \cdot \mathrm{L}^{-1}$. The lake is polymictic due to its shallow depths (mean depth=2.9 m) and generally does not develop stable stratification. Since 1935, the lake's mean depth has been reduced by approximately 0.3 meters as a result of high sediment and nutrient loading from its predominantly agricultural watershed. Water quality and clarity of the turbid lake (mean Secchi transparency $=0.35 \mathrm{~m}$ ) have declined dramatically since the mid-1970s and by an order of magnitude this century. Macrophyte abundance and diversity have also declined with reductions in water clarity, and the lake appears to be in a stable turbid state. A recent photograph of the lake is included in Figure 5.

$<$ Figure 5 near here $>$

A team of limnologists and economists designed a mail survey detailing the current conditions of the lake in terms of water clarity, color, odor, abundance of fish, and the frequency of algae blooms and beach closings. Visitors were also informed that the Iowa Department of Natural Resources was considering steps to improve water quality. The survey included figures depicting the lake's current conditions as well as one of two possible scenarios for improved water quality conditions. These are presented in Figures 6 and 7 respectively.

$<$ Figure 6 near here $>$

$<$ Figure 7 near here $>$

To estimate the value of improved water quality, Clear Lake visitors completed a survey asking how many trips they took to Clear Lake over the past season $\left(y_{i 1}\right)$ and how many trips they would have taken had the water quality been improved as described in the survey $\left(y_{i 2}\right)$. 
Since each visitor reported two trip levels, and the trips are discrete counts, we use a bivariate count data model to estimate the value of improved water quality. To account for the overdispersion and expected correlation between the trip counts, we use a Poisson-lognormal mixture model. For the regression analysis, each visitor's expected current trips from the Poisson-lognormal distribution is denoted as $\lambda_{i 1}$, and each visitor's higher expected improved water quality trips is denoted as $\lambda_{i 2}$, where $i$ denotes the visitor, and the numbers 1 and 2 denote the current and improved state of the lake respectively. We estimate these trip parameters as

$$
\begin{aligned}
& \lambda_{i 1}=\exp \left(\alpha_{1}+\beta_{\text {Cost } 1} \operatorname{Cost}_{i}+\beta_{\text {Inc1 }} \operatorname{Inc}_{i}+\beta_{A g e} \text { Age }_{i}+\beta_{A g e^{2}} A g e_{i}^{2}+\beta_{E d u} E d u_{i}\right) \\
& \lambda_{i 2}=\exp \left(\alpha_{2}+\beta_{\text {Cost } 2} \operatorname{Cost}_{i}+\beta_{\text {Inc2 } 2} I n c_{i}+\beta_{A g e} A g e_{i}+\beta_{A g e^{2}} A g e_{i}^{2}+\beta_{E d u} E d u_{i}+\gamma D_{i}\right),
\end{aligned}
$$

where Cost $_{i}$ represents the travel costs, $I n c_{i}$ represents the visitor's income, $A g e_{i}$ and $A g e_{i}^{2}$ represent the visitor's age and age squared, and $E d u_{i}$ is a dummy variable equal to 1 if the visitor has attended college. The survey contained two different water quality improvement plans, with visitors presented with either a small or a large water quality improvement. $D_{i}$ is a dummy variable equal to 1 for the large improvement and equal to 0 for the small improvement. In this way, we can estimate the use value for both small and large water-quality improvements. Maximum simulated likelihood is used to estimate the model and the model also corrects for the non-random selection of visitors surveyed.

Visitors' data are summarized in Table 1. On average, visitors reported taking 3.0 trips per year to Clear Lake given current water quality conditions. The number of predicted visits increased to an average of 4.1 trips given the small water quality improvement and 6.6 trips given the large improvement. Results from the travel cost regression and the resulting WTP values are reported in Table 2. All of the coefficients have the expected sign, with visitors taking 
more trips to Clear Lake as their travel cost decreases and their income increases. The quadratic age terms indicate that the youngest and oldest visitors, who are expected to have more free time, are more likely to visit Clear Lake. The coefficient on the education dummy variable indicates that visitors who attended college make fewer trips to Clear Lake. The positive coefficient associated with the dummy variable $D_{i}$ indicates that the visitors are expected to take more trips to Clear Lake when there is a large water quality improvement than when there is only a small improvement.

$<$ Table 1 near here $>$

$<$ Table 2 near here $>$

Using these coefficients, we estimate WTP for the small or large water-quality improvement scenarios as the additional CS from the lager number of reported trips to Clear Lake,

$$
\begin{aligned}
W T P_{i} & =C S_{i 2}-C S_{i 1} \\
& =\left(\frac{y_{i 2}}{-\widehat{\beta}_{\text {Cost } 2}}\right)-\left(\frac{y_{i 1}}{-\widehat{\beta}_{\text {Cost } 1}}\right),
\end{aligned}
$$

where $y_{i j}$ is the visitor's reported trip levels and $\widehat{\beta}_{\text {Cost }}$ is the coefficient on the travel costs, and the numbers 1 and 2 again denote the current and improved state of the lake. The average WTP values reported in Table 3 are found by calculating each visitor's WTP, summing WTP across visitors, and dividing by the number of visitors in the study. WTP for the small water-quality improvement is $\$ 139$ per visitor per year, and WTP for the large water quality improvement is \$347 per visitor per year. (These and all WTP estimates are reported in 2000 U.S. dollars.) Visitors report a significantly larger increase in trips given the large water quality improvement plan, reflected in the higher WTP value. 
$<$ Table 3 near here $>$

\section{Stated preferences and the contingent valuation method}

An alternative approach for gathering nonmarket data is the contingent valuation method. The contingent valuation method makes use of survey questions to estimate the respondents' WTP for specified improvements to an environmental amenity, such as a lake or river. Contingent valuation is considered a stated preference technique because respondents answer direct questions about their WTP for proposed changes, and therefore state their preferences.

Survey respondents are typically presented with a three-part survey instrument: (1) a detailed description of the good being valued and the hypothetical circumstances under which it will be made available, (2) questions eliciting respondents' WTP for the good, and (3) questions about the respondents' demographic characteristics. The most common format for the valueelicitation question is a hypothetical ballot initiative where the respondents vote "yes" if they are willing to pay a given monetary value for a proposed water quality improvement. For example, "Would you be willing to pay \$X to improve the water quality of Smith Lake?"

The importance of contingent valuation in U.S. law is underscored by Executive Order 12044 issued by President Carter in 1978 which required federal agencies to consider both the costs and benefits of potential regulatory actions, and by the 1980 federal Comprehensive Environmental Response, Compensation and Liability Act which officially recognized contingent valuation as a technique for estimating environmental damages caused by chemical spills. The contingent valuation method first gained widespread notoriety after the Exxon Valdez oil spill, which lead to the Oil Pollution Act of 1990 and the subsequent National Oceanic and Atmospheric Administration Panel report on the reliability of contingent valuation as a means of 
assessing legal damages. The panel ultimately supported the use of contingent valuation in assessing damages so long as studies followed the panel's guidelines, among which were the recommendations to use referendum-style valuation questions, that respondents be reminded of their limited budgets, and that respondents be informed of the existence of substitute goods.

While originally developed in the USA, the contingent valuation method is increasingly being put to use abroad. Examples include studies estimating Britons' WTP to prevent saline flooding of the Norfolk Broads, a freshwater wetland in East Anglia near the North Sea; and Filipinos' WTP for improved access to sanitary water and sewer services. Worldwide, the contingent valuation method has had less of an impact on policy decisions than in the USA. For example, while dozens of contingent valuation studies have been conduced in Europe, the EU has no formal procedures for integrating the results of such studies into policymaking. This is likely due to Europeans being less comfortable with the idea of assigning monetary values to environmental amenities.

Contingent valuation is widely used in the environmental valuation literature, where it is generally accepted that the value of certain nonmarket goods can only be estimated using contingent valuation or other similar stated preference techniques. For example, consider Americans' WTP to preserve Alaska's Artic National Wildlife Refuge. Only the contingent valuation method can estimate the full WTP for preservation, as the travel cost method would estimate only the recreational value of those who actually visit the refuge.

Contingent valuation's primary appeal is its flexibility. By creating a hypothetical market where no real market exists, contingent valuation allows economists to estimate values that would be difficult, if not impossible, to estimate using revealed preference techniques. 
Economists have used the technique to value goods as varied as increased visibility, the existence of endangered species, and public libraries.

\section{An application of the contingent valuation method}

As part of the Clear Lake study described above, we were also interested in estimating local residents' WTP for improved water quality. Because the cities of Clear Lake and Ventura, Iowa are located adjacent to the lake, the negligible travel cost residents incur when visiting the lake would dramatically understate the value they place on water quality. This is an excellent example of a situation where stated preference techniques may provide more meaningful results than revealed preference techniques.

Prior to mailing, the CVM survey was presented to a focus group of local residents to test its clarity and realism. This survey was followed by a mailed pretest. In its final form, we mailed the survey to a random sample of 900 local households. Of the 900 surveys, 768 were successfully delivered. Of these, 513 were returned by respondents for a respectable $67 \%$ response rate, though only 479 of the returned surveys were complete. A summary of respondents' socioeconomic characteristics is presented in Table 4.

$<$ Table 4 near here $>$

Residents answered a referendum-format contingent valuation question designed to elicit their WTP for the small water-quality improvement scenario described in the previous section. Specifically, residents answered questions such as the following:

Would you vote "yes" on a referendum that would adopt the proposed program, but cost you $\$ 900$ (paid over five years at $\$ 180$ per year)? 
The proposed cost or policy price was varied across respondents, ranging from $\$ 135$ to $\$ 1260$. Plotting responses allows us to come up with a rough estimate of the highest price at which the referendum would pass. The proportion of residents voting yes when faced with policy prices falling into each of several ranges is reported in Table 5. These same results are shown graphically in Figure 8. The figure suggests that the highest policy price at which half of residents would vote in favor of the small water quality improvement was roughly $\$ 550$.

$<$ Table 5 near here $>$

$<$ Figure 8 near here $>$

We use regression analysis to arrive at a more formal WTP estimate. The probability that resident $i$ votes in favor of the proposed policy can be written as

$$
\operatorname{Pr}\left(\text { Yes }_{i}=1\right)=\operatorname{Pr}\left(W T P_{i}>P_{i}\right),
$$

where $W T P_{i}$ is resident $i$ 's WTP and $P_{i}$ is the policy price resident $i$ faces. Assuming $W T P_{i}$ is a linear function of resident $i$ 's income, age, age squared, and educational attainment, we can rewrite (4) as

$$
\operatorname{Pr}\left(\text { Yes }_{i}=1\right)=\operatorname{Pr}\left(\alpha+\beta_{\text {Inc }} I n c_{i}+\beta_{A g e} A g e_{i}+\beta_{A g e^{2}} A g e_{i}^{2}+\beta_{E d u} E d u_{i}+\sigma \varepsilon_{i}>P_{i}\right),
$$

where $\varepsilon_{i}$ is a standard normal error term. Taking advantage of the symmetry of the standard normal distribution, we can rewrite (5) as

$$
\operatorname{Pr}\left(\text { Yes }_{i}=1\right)=\operatorname{Pr}\left(\frac{\alpha+\beta_{\text {Inc }} I n c_{i}+\beta_{A g e} A g e_{i}+\beta_{A g e^{2}} A g e_{i}^{2}+\beta_{E d u} E d u_{i}-P_{i}}{\sigma}>\varepsilon_{i}\right)
$$

The probit routine from any standard statistical package can be used to estimate the probability of a yes response as a function of a constant term, socioeconomic variables, and the policy price. The results of the probit regression described in equation (6) are presented in Table 
6. The coefficients associated with education and income are significant at the $5 \%$ and $1 \%$ levels respectively, suggesting that WTP increases with educational attainment and income.

Specifically, attending college results in a $\$ 470$ increase in estimated WTP, while an additional $\$ 10,000$ in household income results in a $\$ 105$ increase in estimated WTP. As expected, the policy-price coefficient is significantly less than zero (at the $1 \%$ level). Given our specification, this result suggests that the likelihood of a yes vote falls as the policy price increases.

$<$ Table 6 near here $>$

We can use the regression results reported in Table 6 to estimate mean WTP as

$$
\overline{W T P}=\left(\frac{\hat{\alpha}}{\sigma}+\frac{\hat{\beta}_{A g e}}{\sigma} \overline{A g e}+\frac{\hat{\beta}_{A g e^{2}}}{\sigma} \overline{A g e^{2}}+\frac{\hat{\beta}_{I n c}}{\sigma} \overline{I n c}+\frac{\hat{\beta}_{E d u}}{\sigma} \overline{E d u}\right) /\left(\frac{\hat{1}}{\sigma}\right),
$$

where the bars represent sample means and the hats represent coefficient point estimates. Using this formula, we estimate residents' mean WTP for improved water quality to be $\$ 512$.

More formal analyses might allow for nonlinear WTP functions or might restrict WTP to be greater than zero and less than a household's annual income.

\section{Conclusions}

This Chapter summarizes and provides examples of the two most common approaches for estimating the value of public goods, focusing on the aesthetic value of lakes and rivers. We have applied these techniques to estimate willingness to pay (WTP) for improved water quality conditions at a eutrophic lake in an agricultural region of the USA. The first approach, the travel cost method, infers visitors' WTP for water quality by estimating the change in consumer surplus (CS) from access to the lake before and after proposed water quality improvements. CS is estimated using individual variation in trips taken, recognizing that visitors incur different travel 
costs. The second approach, the contingent valuation method, involves asking respondents direct questions about their WTP for water quality improvements. As such, this method can estimate full WTP, not just WTP for improved recreational opportunities.

As expected, visitors place more value on a large water-quality improvement than on a small one. Local residents are also willing to pay a substantial amount for improved water quality, which is not surprising given that residents regularly benefit from the lake's scenic qualities and that their housing values and business revenues could be enhanced by beautification of the lake.

While either the travel cost or the contingent valuation method lead to valid benefit estimates which can used in cost-benefit analyses, the methods have different strengths. Travel cost estimates are less controversial since they are based on actual behavior (i.e., trips taken). The contingent valuation method, on the other hand, offers more flexibility because of its hypothetical nature. As a result, it can be used to analyze policy scenarios that could not be examined with revealed preference techniques. For example, in the study detailed above the travel cost method cannot be used to estimate local residents' WTP, as there is very little travel cost variation among residents who all live near the lake. 


\section{Further Reading}

Arrow, K.J., Bateman, I.J. and Willis, K.G. (eds.) (2001). Valuing environmental preferences: theory and practice of the contingent valuation method in the US, EU, and developing countries. Oxford, UK: Oxford University Press.

Arrow, K.J., Solow, R.M., Leamer, E.E., et al. (1993). Natural resource damage assessments under the Oil Pollution Act of 1990. Federal Register 58, 355-379.

Carson, R.T. (2007). Contingent valuation: a comprehensive bibliography and history. Cheltenham, UK: Edward Elgar.

Carson, R.T. and Hanemann, W.M. (1992). A preliminary economic analysis of recreational fishing losses related to the Exxon Valdez oil spill. A Report to the Attorney General of the State of Alaska.

Diamond, P.A. and Hausman, J.A. (1994). Contingent valuation: is some number better than no number? Journal of Economic Perspectives 8, 45-64.

Freeman, A.M. (2003). The measurement of environmental and resource values: theory and methods. Washington, DC: Resources for the Future.

Haab, T.C. and McConnell, K.E. (2002). Valuing environmental and natural resources: the econometrics of nonmarket valuation. Cheltenham, UK: Edward Elgar.

Herriges, J.A. and Kling, C.L. (eds.) (1999). Valuing recreation and the environment: revealed preference methods in theory and practice. Cheltenham, UK: Edward Elgar.

Loomis, J.B. (2005). Economic values without prices: the importance of nonmarket values and valuation for informing public policy debates. Choices 20, 179-82.

Mitchell, R.C. and Carson, R.T.. (1989). Using surveys to value public goods: the contingent valuation method. Washington, DC: Resources for the Future. 


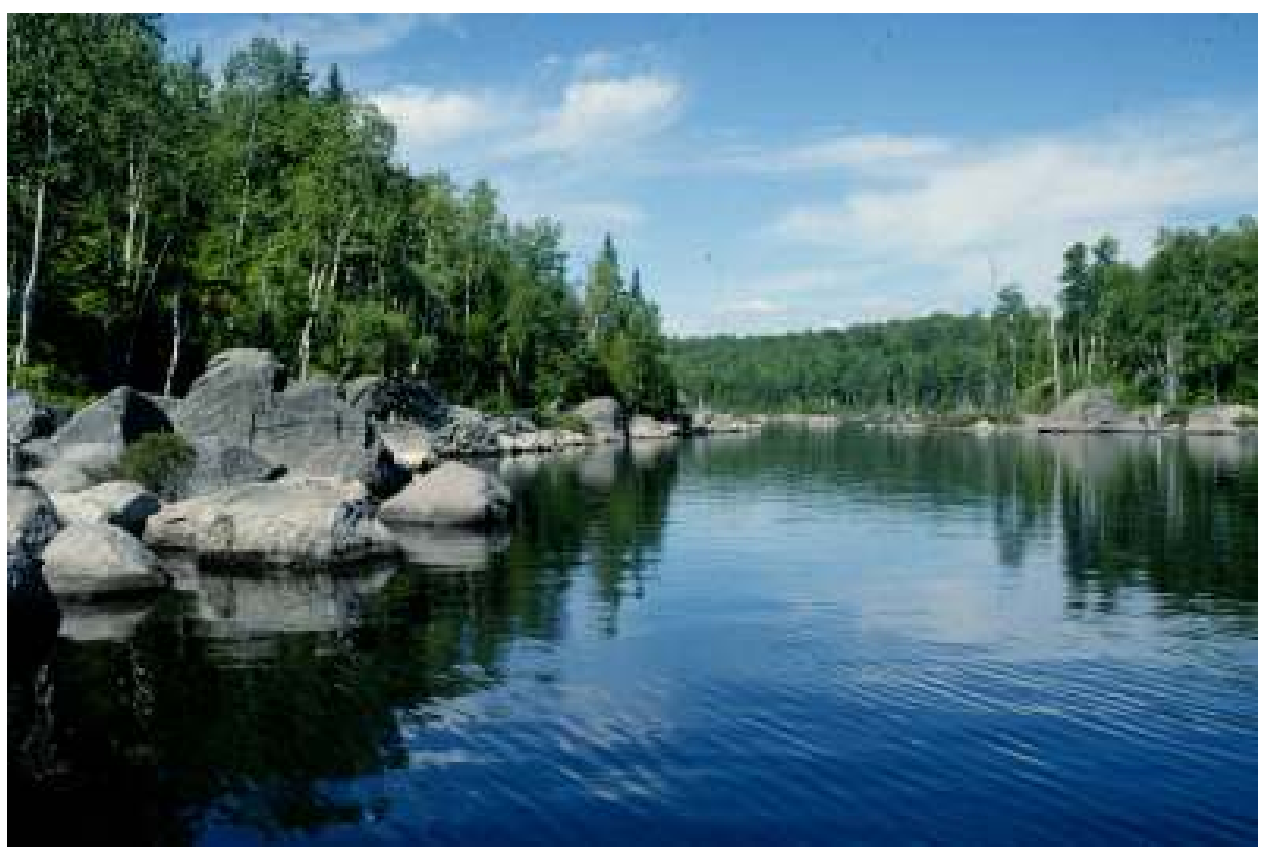

Figure 1. A pristine, oligotrophic lake on the Canadian shield north of Montreal, Canada. The paucity of nutrients in these ecosystems yield balanced ecological conditions that enhance the natural beauty and human enjoyment of recreation. 


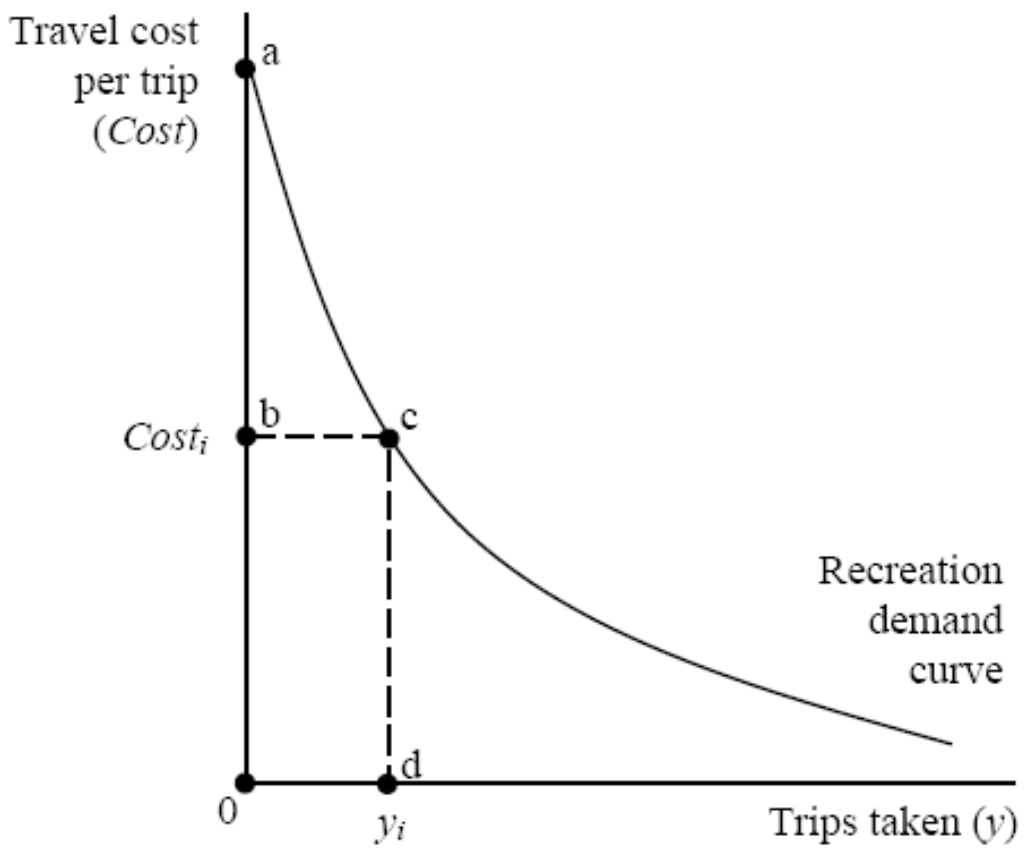

Figure 2. Illustration of a recreation demand curve for a particular water resource, showing the inverse relationship between travel costs per trip and the number of times individuals choose to visit the site. 

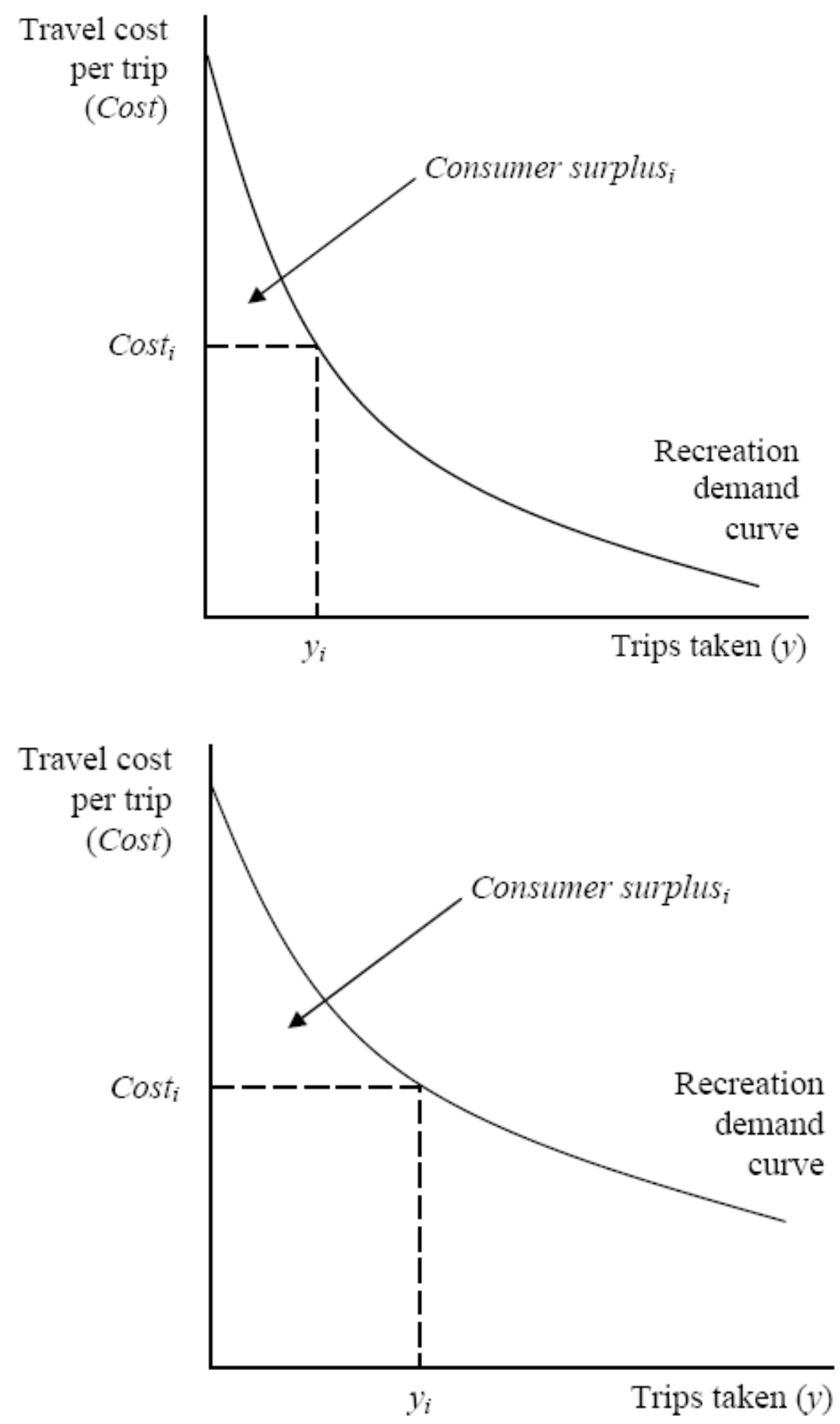

Figure 3. (a) Illustration of a recreation demand curve and the resulting CS for a site with moderate aesthetic quality. (b) Illustration of a recreation demand curve and the resulting CS for a site with high aesthetic quality. 


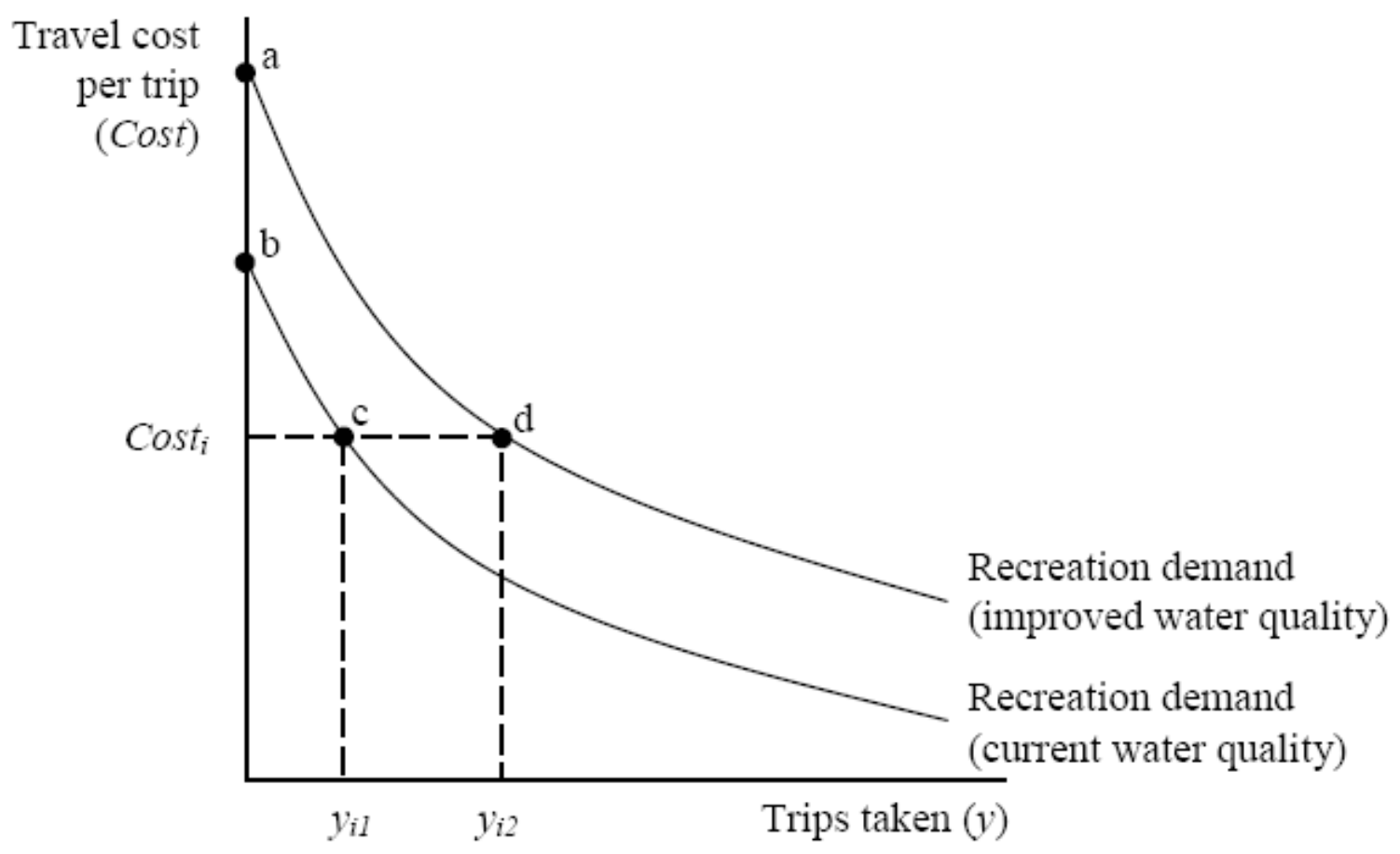

Figure 4. Illustration of two recreation demand curves, one with current aesthetic quality and the other with improved aesthetic quality, showing WTP for the improved aesthetic quality scenario as the additional CS derived. 


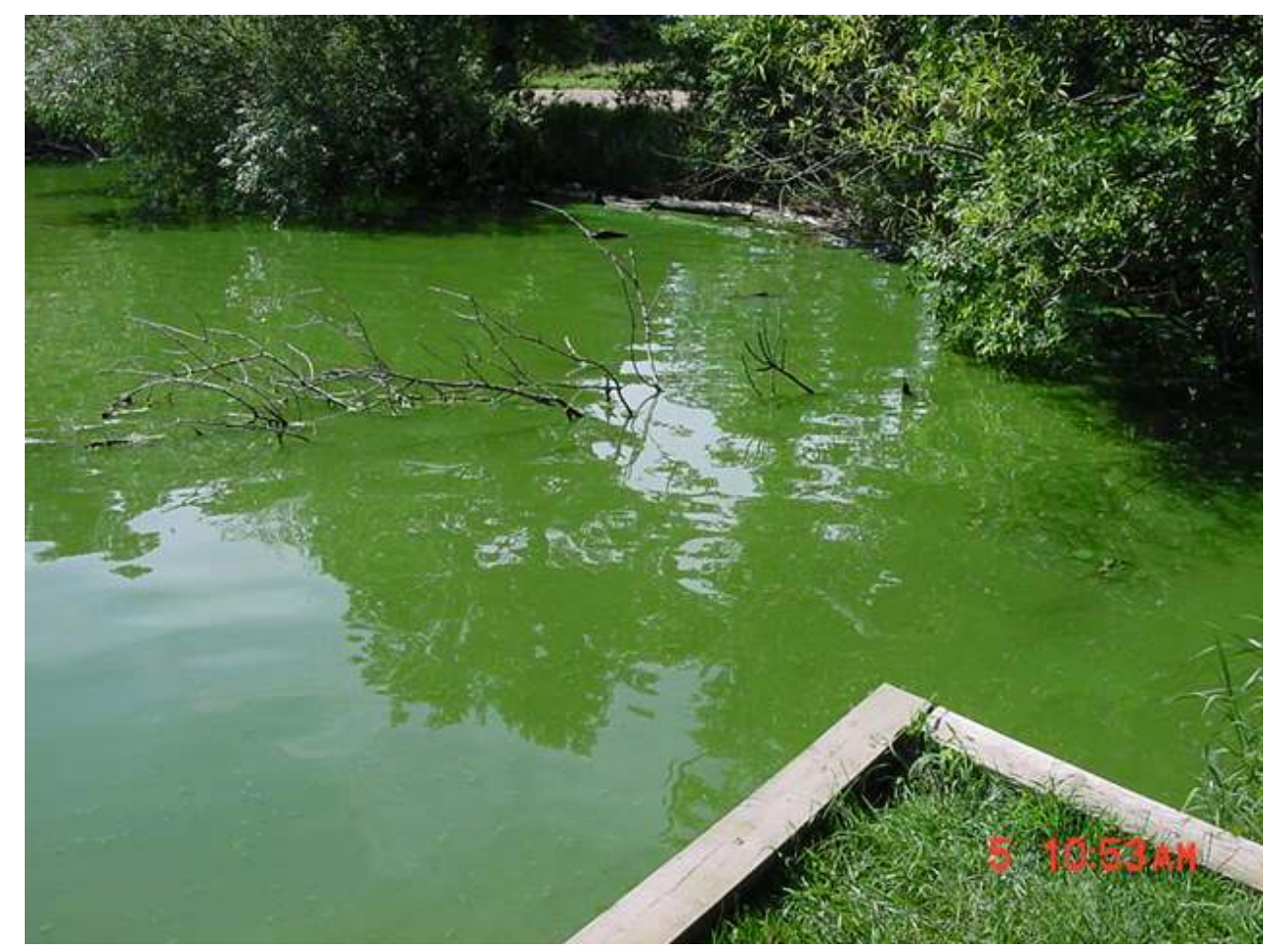

Figure 5. Super-abundant nutrients such as those found in Clear Lake, Iowa, USA, yield eutrophic algae that impede recreational value. 


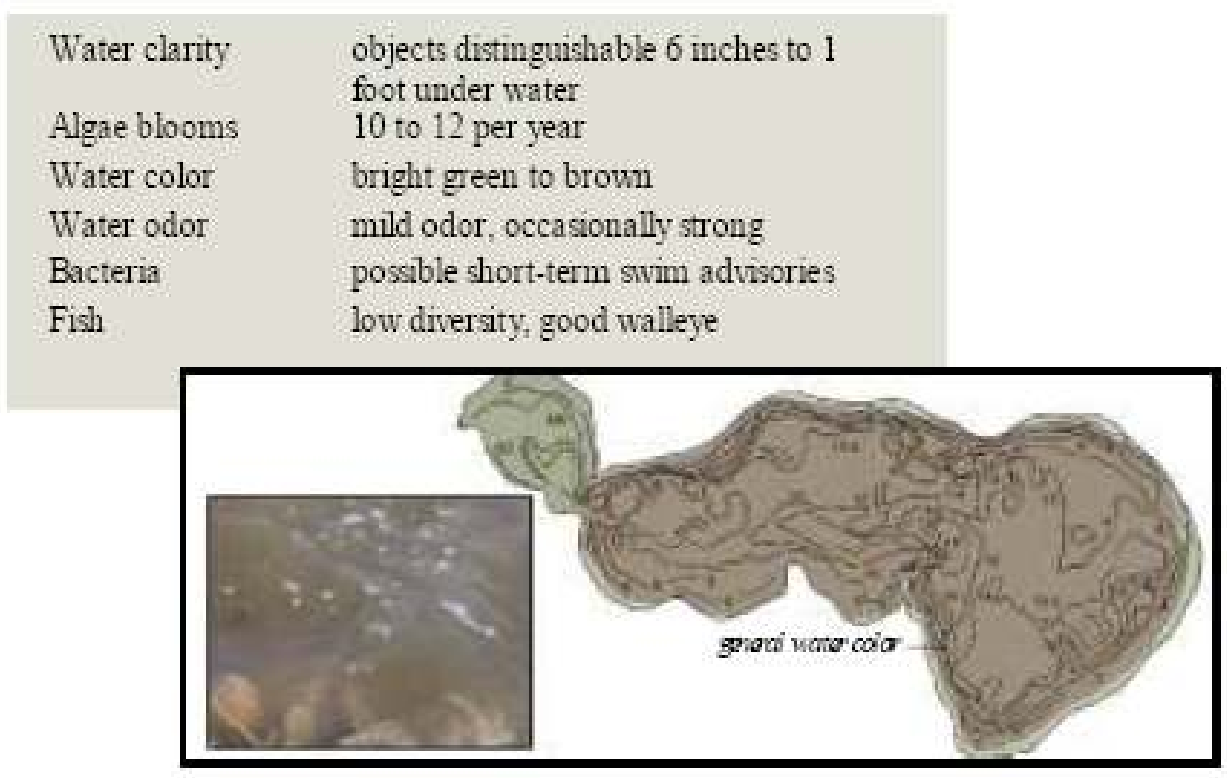

Figure 6. Survey information provided to respondents concerning Clear Lake's current water quality. Respondents were told that "Overall, the current conditions of Clear Lake can be summarized in terms of:" 

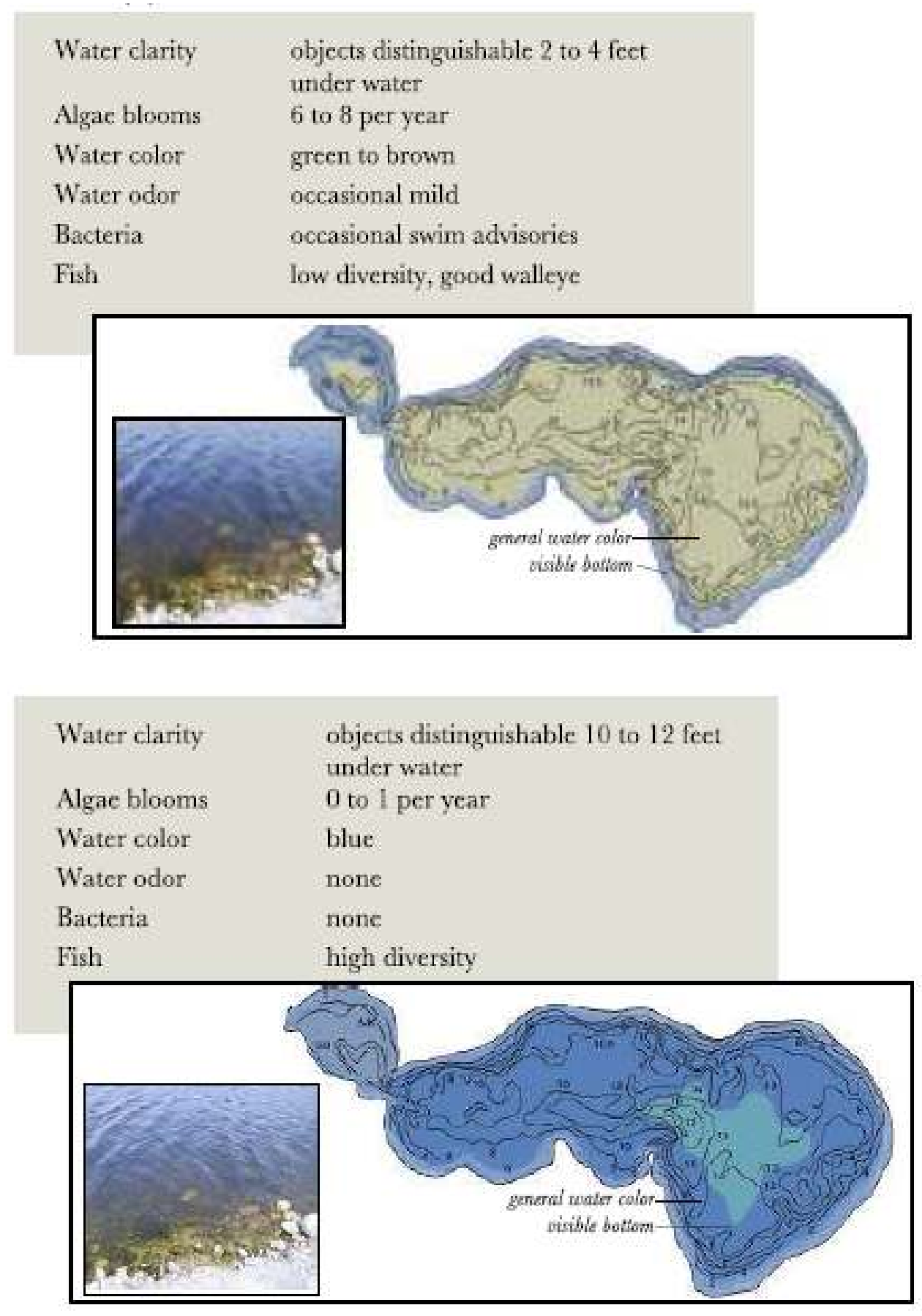

Figure 7. Survey information provided to respondents concerning possible future water quality improvements. Respondents were told, "Suppose that investments could be made to actually improve the quality of Clear Lake. These investments might include establishing protection strips along the edge of the lake to reduce runoff from the surrounding area or other structural changes to the lake. Theses changes would improve the lake over the next five to then years to the following conditions:". 


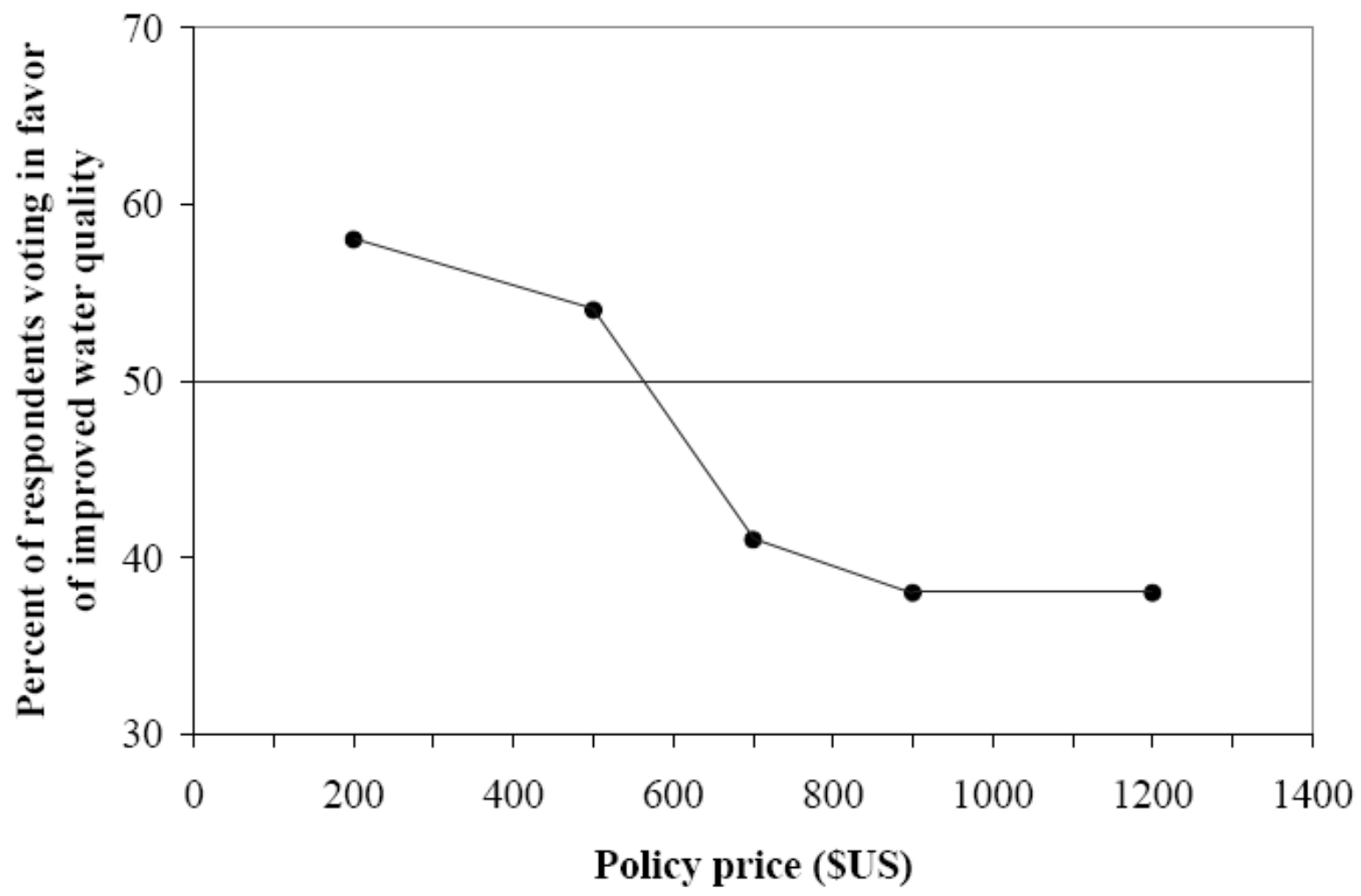

Figure 8. Relationship between the hypothetical price required to maintain current levels of water quality and the raw percentage of visitors voting yes. The actual maximum price that would be passed by referendum was estimated following equation (6). 
Table 1. Summary of the characteristics for the 389 respondents to the visitors' survey. "Std. dev." denotes the sample standard deviation. The mean estimates are corrected for the nonrandom sampling.

\begin{tabular}{llcccc}
\hline \hline Variable & Definition & Mean & Std. dev. & Min. & Max. \\
\hline Trips $\left(y_{i 1}\right)$ & $\begin{array}{l}\text { Trips given current water quality } \\
\text { conditions }\end{array}$ & 3.0 & 11.6 & 1 & 50 \\
Trips $\left(y_{i 2 S}\right)$ & $\begin{array}{l}\text { Trips given a small water quality } \\
\text { improvement }\end{array}$ & 4.1 & 15.2 & 1 & 100 \\
Trips $\left(y_{i 2 L}\right)$ & $\begin{array}{l}\text { Trips given a large water quality } \\
\text { improvement } \\
\text { Cost }\end{array}$ & 6.6 & 16.4 & 1 & 100 \\
Travel costs per trip & 95.13 & 57.53 & 5.40 & 294.63 \\
Ancome & Total household income & 63,000 & 38,000 & 7,500 & 200,000 \\
Education & The respondent's age & 43 & 13 & 15 & 82 \\
\hline \hline
\end{tabular}


Table 2. Travel cost method regression results of the bivariate Poisson-lognormal model. All of the coefficients are scaled by 100, except the constants (which are unscaled), and the income coefficient (which is scaled by 100,000). Standard errors are in parentheses. "**" and "**" indicate statistical significant at $5 \%$ and $1 \%$ levels respectively.

\begin{tabular}{|c|c|c|}
\hline Variable & Coefficient & Coefficient point estimate \\
\hline Constant $\left(y_{i 1}\right)$ & $\alpha_{1}$ & $1.89^{* *}(0.29)$ \\
\hline Constant $\left(y_{i 2}\right)$ & $\alpha_{2}$ & $2.97^{* *}(0.27)$ \\
\hline Intercept dummy & $\gamma$ & $23.0^{* *}(4.3)$ \\
\hline Travel cost $\left(y_{i 1}\right)$ & $\beta_{\text {Cost } 1}$ & $-1.43^{* *}(0.13)$ \\
\hline Travel cost $\left(y_{i 2}\right)$ & $\beta_{\text {Cost } 2}$ & $-1.18^{* *}(0.10)$ \\
\hline Income $\left(y_{i 1}\right)$ & $\beta_{\text {Inc1 }}$ & $1.54^{* *}(0.17)$ \\
\hline Income $\left(y_{i 2}\right)$ & $\beta_{\text {Inc } 2}$ & $1.08^{* *}(0.13)$ \\
\hline Age & $\beta_{\text {Age }}$ & $-6.96^{* *}(1.30)$ \\
\hline $\operatorname{Age}^{2}$ & $\beta_{A g e^{2}}$ & $0.063^{* *}(0.014)$ \\
\hline Education & $\beta_{E d u}$ & $-25.7^{* *}(8.7)$ \\
\hline$y_{i 1}$ trip variance & $\sigma_{1}$ & $1.24^{* *}(0.05)$ \\
\hline$y_{i 2}$ trip variance & $\sigma_{2}$ & $0.97^{* *}(0.04)$ \\
\hline$\sigma_{1}$ and $\sigma_{2}$ correlation & $\rho$ & $0.98^{* *}(0.006)$ \\
\hline Sample size & & 389 \\
\hline Log likelihood & & $-2,362$ \\
\hline
\end{tabular}


Table 3. Travel cost method results showing consumer surplus estimates for current and improved water quality scenarios as well as the mean annual WTP per visitor to improve water quality conditions. Standard errors are in parentheses. Calculations follow equation 3.

\begin{tabular}{cc}
\hline \hline & Mean annual Consumer Surplus \\
$C S_{1}$ & $\$ 212(20.4)$ \\
$C S_{2 S}$ & $\$ 351(29.4)$ \\
$C S_{2 L}$ & Mean annual WTP for the small water quality improvement \\
\hline$W T P_{S}$ & $\$ 139(36.0)$ \\
\hline$W T P_{L}$ & Mean annual WTP for the large water quality improvement \\
\hline \hline
\end{tabular}


Table 4. Summary of the characteristics for the 479 respondents to the residents' survey. "Std. dev." denotes the sample standard deviation.

\begin{tabular}{llcccc}
\hline \hline Variable & Definition & Mean & Std. dev. & Minimum & Maximum \\
\hline Income & Total household income & 56,000 & 41,000 & 7,500 & 200,000 \\
Age & The respondent's age & 54 & 15 & 15 & 82 \\
Education & 1 if attended college & 0.71 & 0.44 & 0 & 1 \\
\hline \hline
\end{tabular}


Table 5. The number and percentage of residents voting yes when faced with policy prices falling into each of several ranges

\begin{tabular}{cccc}
\hline Policy price range & $\begin{array}{c}\text { Number of } \\
\text { respondents } \\
\text { voting yes }\end{array}$ & $\begin{array}{c}\text { Total number of } \\
\text { respondents }\end{array}$ & $\begin{array}{c}\text { Percentage of } \\
\text { respondents } \\
\text { voting yes }\end{array}$ \\
\hline$\$ 0-\$ 399$ & 34 & 59 & $58 \%$ \\
$\$ 400-\$ 599$ & 44 & 81 & $54 \%$ \\
$\$ 600-\$ 799$ & 41 & 101 & $41 \%$ \\
$\$ 800-\$ 999$ & 57 & 151 & $38 \%$ \\
$\$ 1000-\$ 1399$ & 33 & 87 & $38 \%$ \\
\hline \hline
\end{tabular}


Table 6. Contingent valuation regression results. Results were derived following equation (6). All of the coefficients are scaled by 100, except the constant (which is unscaled), and the income coefficient (which is scaled by 100,000). Standard errors are shown in parentheses. "*" and “**” indicate statistical significant at $5 \%$ and $1 \%$ levels respectively.

\begin{tabular}{ccc}
\hline \hline Variable & Coefficient & Coefficient point estimate \\
\hline Constant & $\frac{\alpha}{\sigma}$ & 0.586 \\
Income & $\frac{\beta_{I n c}}{\sigma}$ & $(0.689)$ \\
& $\frac{\beta_{A g e}}{\sigma}$ & $(0.163)$ \\
Age & $\frac{\beta_{A g e^{2}}}{\sigma}$ & -3.53 \\
Age & $\frac{\beta_{E d u}}{\sigma}$ & $(2.47)$ \\
Education & $-\frac{1}{\sigma}$ & $(0.0222)$ \\
Policy price & & $34.1 *$ \\
Sample size & & $-0.0726^{* *}$ \\
Log likelihood & & $(0.0216)$ \\
Mean WTP & & 479 \\
\hline \hline
\end{tabular}




\section{Cross References}

Chapter 4, Aquatic ecosystem services

Chapter 17, Lakes and reservoirs

Chapter 33, Lakes and reservoirs of North America

Chapter 75, Turbidity

Chapter 141, Eutrophication of lakes and reservoirs

Chapter 198, Lakes as ecosystems

Chapter 238, Agriculture

Chapter 239, Harmful algal blooms

Chapter 241, Conservation of aquatic ecosystems

Chapter 242, Tourism, recreation

Chapter 244, Lake management, criteria

Chapter 245, Lake and reservoir management 


\section{Glossary of Terms}

"Consumer surplus" (CS) is the difference between the maximum amount individuals are willing to pay for a good and the cost they actually incur, summed across all units consumed.

"Contingent behavior trips" are the trips individuals report they would take following a hypothetical scenario, such as a water quality improvement at a lake. These trips are contingent upon the hypothetical scenario.

The "contingent valuation method" is a stated-preference technique for estimating the value of nonmarket goods. Survey respondents may be asked to name the most they would be willing to pay in exchange for a nonmarket good, or, more commonly, whether they would be willing to pay a specified amount in exchange for that good. The results provide direct insight into the monetary value associated with the nonmarket good in question.

"Cost-benefit analysis" refers to a systematic weighing of the total costs of a proposed policy or action against the total benefits. A policy is said to fail the cost-benefit test if the total costs associated with implementing the policy exceed the total benefits that would be derived. If policymakers must chose among several policies that pass the cost-benefit test, they should choose those where the benefits exceed the costs by the largest proportion.

"Maximum simulated likelihood" is a method of regression analysis. The likelihood function is the joint probability density function of the data sample, and is interpreted to be a function of the set of parameter values. The objective is to choose the coefficients that maximize the likelihood function. Simulation is needed when the likelihood function does not have a closed form, i.e., it can't be solved analytically.

"Nonmarket goods" are products or services which cannot be bought or sold in a conventional market setting. Examples include clean air or pristine wilderness.

A "Poisson-lognormal mixture model" is a Poisson model with a lognormally distributed error term in the mean. The Poisson distribution only has one parameter, $\lambda_{i}$, and to utilize the distribution as a regression analysis, $\lambda_{i}$ is specified as a function of independent variables, as given in equation 2 . This distribution does not have a closed form, therefore maximum simulated likelihood is used for estimation of the coefficients

"Polymictic" is a mixing regime characterized by frequent summer mixing events interspersed with periods of weak thermal stratification.

"Public goods" are products or services that are nonexcludable (i.e., once the good is made available it is difficult or very costly to keep those who have not paid from consuming it) and nonrival in consumption (i.e., one person's consumption of the good does not detract from another person's consumption of the very same good).

A "probit regression" is a form of regression analysis used when the variable of interest (the dependent variable) is binary and the additive error is from a standard normal distribution. 
"Regression analysis" is a functional relationship between dependent variables and selected independent variables (explanatory variables), with the objective being the explanation of the dependent variable's variation across observations.

"Revealed-preference techniques" are those valuation methods where the researcher observes an individual's actions, and based on those actions is able to make inferences about the individual's willingness to pay for a nonmarket good. In this sense, revealed-preference techniques represent in indirect method for estimating the value of nonmarket goods. The travel cost method is the most commonly used revealed-preference technique.

"Stated-preference techniques" are those valuation methods where the researcher asks individuals questions the answers to which provide a direct measure of their willingness to pay for a nonmarket good. The contingent valuation method is the most commonly used statedpreference technique.

The "travel cost method" is a revealed-preference technique for estimating the value of a recreational site. Survey respondents are asked how many trips they have made or plan to make to the site over a given time period. The distance and time are monetized based on the cost of making a trip and the wages forgone while traveling. Individuals who are willing to incur $\$ \mathrm{X}$ in travel costs to visit a recreational site reveal that they are willing to pay at least that much for the visit.

"Willingness to pay" (WTP) refers to the maximum monetary value an individual is prepared to forgo in order to consume a good. 